Journal of Research in Interprofessional

Practice and

Education

Vol. 5.2

October 2015
Journal of Research in Interprofessional Practice and Education (JRIPE)

Vol. 5.2

(C) 2015

Corresponding author: Paul Holyoke. Email: paulholyoke @saintelizabeth.com

\section{Observe, Coach, Assist, and Report: An Emerging Framework for Integrating Unregulated Healthcare Providers into Interdisciplinary Healthcare Teams}

\author{
Justine L. Giosa, MSc; Paul Holyoke, PhD; Danielle Bender, MA; \\ Sandra G. Tudge, MSW; \& Wendy Gifford, RN, PhD
}

\begin{abstract}
Background: Unregulated healthcare providers known as personal support workers (PSWs) provide the majority of home care services in Ontario, Canada. However, there is little direction to guide their activities as members of interdisciplinary healthcare teams. The purpose of this study was to explore and describe the role of PSWs in interdisciplinary evidence-based stroke care.

Methods and Findings: A concurrent triangulation mixed-methods design was used. Data sources included surveys $(N=270)$, chart audits $(N=234)$, interviews $(N=28)$, focus groups $(N=7)$, textbook review, an advisory committee $(N=14)$, and knowledge fairs $(N=112)$. PSWs can participate in team-based stroke care by observing vital information about clients in their homes, coaching clients to follow care plans, assisting to implement recommendations made by other healthcare providers, and reporting client progress, challenges, needs, and preferences to the healthcare team.

Conclusions: The Observe, Coach, Assist, and Report (OCAR) themes have the potential to be used as a framework to guide improvements in intra-team communication, information sharing, and awareness of the PSW role, in order to support a more integrated home care experience for clients and families. Next steps include pilot testing the OCAR framework at the point of care in various settings to enhance interdisciplinary collaboration that is inclusive of PSWs.
\end{abstract}

Keywords: Personal support worker; Unregulated healthcare provider; Interdisciplinary; Home care; Rehabilitation

\section{Introduction}

Personal support workers (PSWs) are unregulated healthcare providers who work in a variety of Canadian healthcare settings, including, but not limited to, acute hospital care, in-patient rehabilitation, long-term care (LTC), and home and community care. In Canada, they are also known by a variety of other titles, such as healthcare aide/assistant, home care assistant, and continuing care assistant [1].

In 2013-2014, PSWs delivered approximately 73\% of home care services in Ontario, Canada [2]. The demand for home care services, particularly from PSWs, continues to grow with an aging population, person-centred care approaches, and deinstitutionalization initiatives perpetuating the growing shortage of regulated health 
2

Framework for Integrating Unregulated Healthcare Providers into Interdisciplinary Healthcare Teams

Giosa, Holyoke, Bender, Tudge, \& Gifford

Journal of Research in Interprofessional Practice and Education

Vol. 5.2

October 2015 professionals (RHPs), such as registered nurses (RNs), occupational therapists (OTs), speech language pathologists (SLPs), social workers (SWs), or physiotherapists (PTs), to manage the workload in this setting [3].

PSWs working in home care in Ontario are supervised by RHPs-usually RNs. Their role typically encompasses providing assistance with activities of daily living (ADLs) (e.g., bathing), instrumental activities of daily living (IADLs) (e.g., meal preparation), and performing higher-risk "controlled acts" (e.g., injections) delegated by RHPs under the Regulated Health Professions Act, 1991 [4]. This traditionally understood PSW work, however, touches on only part of the range of home care services offered in Canada, which can include health promotion and teaching, curative intervention, end-of-life care, rehabilitation, support and maintenance, social adaptation, and support for family caregivers [5]. While many of these additional home care activities are usually viewed as falling within the scope of practice of RHPs, the prominent and growing involvement of PSWs in the delivery of home care in Ontario demands a more in-depth investigation of the collaboration between PSWs and RHPs-one that looks beyond supervisor-supervisee/regulated-unregulated provider relationships to capitalize on the time PSWs spend with clients, and the knowledge and skills of both PSWs and RHPs, in order to initiate, support, provide, and/or promote the continuity of the full range of available Canadian home services.

Limited published literature exists on the impact and potential of more active and explicit inclusion of PSWs on interdisciplinary healthcare teams, but work in LTC and home care supports the need for further investigation. For example, Kontos, Miller, \& Mitchell [6] investigated the PSW role in care planning for LTC patients and found that their unique knowledge was explicitly excluded due to standardized assessments used by RHPs, which did not capture PSW input. More recently, Kaasalainen, Brazil, \& Kelley [7] investigated the role of experiential learning in building capacity for PSWs to provide palliative care in LTC homes. PSWs shadowed community hospice teams and reported feeling pleased at the level of integration they experienced as members of these teams. In home care, Markle-Reid and colleagues [8] demonstrated that the inclusion of PSWs as members of an interdisciplinary community stroke rehabilitation team led to better patient outcomes compared to usual care. Existing literature clearly supports the need for interdisciplinary home and community care involving PSWs, and the potential for interdisciplinary collaboration with PSWs to improve patient outcomes in stroke care. What is missing from existing evidence is a clear description of the specific role of PSWs on interdisciplinary teams, as well as the type, frequency, and nature of the interactions between PSWs and RHPs required for achieving improved patient outcomes.

In 2011-2012, 50.6\% of Ontario stroke survivors received government-funded home care rehabilitation services, including occupational therapy, physiotherapy, speech language pathology, and/or social work; $29 \%$ received personal support and homemaking services; and 18\% received nursing services [9]. Canadian Stroke Strategy best practice recommendations (CSS-BPRs) have been established to increase the quality of stroke care across the continuum and include recommenda- 
3

Framework for Integrating Unregulated Healthcare Providers into Interdisciplinary Healthcare Teams

Giosa, Holyoke, Bender, Tudge, \& Gifford
Journal of Research in Interprofessional Practice and Education

Vol. 5.2

October 2015 tions for home-based rehabilitation for physicians, RNs, PTs, OTs, SLPs, social workers, dieticians, pharmacists, psychologists, and other disciplines and support staff who provide direct care to stroke patients. The CSS-BPRs acknowledge that unregulated rehabilitation assistants may be part of a stroke survivor's interdisciplinary stroke team, but they do not acknowledge PSWs, nor are there explicit recommendations or activities described for them [10].

The purpose of this study was to investigate an enhanced role for PSWs in the provision of evidence-based stroke rehabilitation and community reintegration within the context of an interdisciplinary stroke team.

The specific research questions were as follows:

- How do PSWs provide support to stroke survivors and their family caregivers at home?

- How are PSWs involved in the implementation of recommendations and care plans made by RHPs according to the CSS-BPRs for rehabilitation and community reintegration?

- To what extent do stroke survivors, caregivers, healthcare providers, educators, and PSWs themselves perceive PSWs to be equipped to provide additional support to stroke survivors and their family caregivers?

- What opportunities exist for PSWs to provide additional support to stroke survivors and their family caregivers within an interdisciplinary stroke care team according to the CSS-BPRs?

\section{Methods}

A concurrent triangulation mixed-methods approach was applied, using a convergence model to bring the data together [11,12]. Qualitative and quantitative data collection and analysis was undertaken simultaneously by different members of the research team. Qualitative and quantitative results were then brought together by the researchers to compare and contrast the findings and develop an overall interpretation of the role of PSWs in interdisciplinary evidence-based home care for stroke survivors and their family caregivers (Figure 1).

An integrated knowledge translation approach (iKT) was used to ensure the research was informed by and grounded in the day-to-day realities of relevant stakeholders involved in interdisciplinary stroke care [13]. Frontline providers, including a PSW, RN, SLP, OT, and PT, were co-investigators of the study to foster a direct link between the research team and the frontline of care. An advisory committee with broad stakeholder representation was formed to guide data collection and inform data analysis and interpretation. The advisory committee included a stroke survivor and family caregiver; academic researchers; practitioners from rehabilitation therapies and nursing; and representatives from the organization responsible for coordinating government-funded home care services, a community college, and the Ontario Stroke Network. The advisory committee met five times over the course of the research study in meetings facilitated by the researchers as focus groups. 
4

Framework for Integrating Unregulated Healthcare Providers into Interdisciplinary Healthcare Teams

Giosa, Holyoke, Bender, Tudge, \& Gifford
Journal of Research in Interprofessional Practice and Education

Vol. 5.2

October 2015

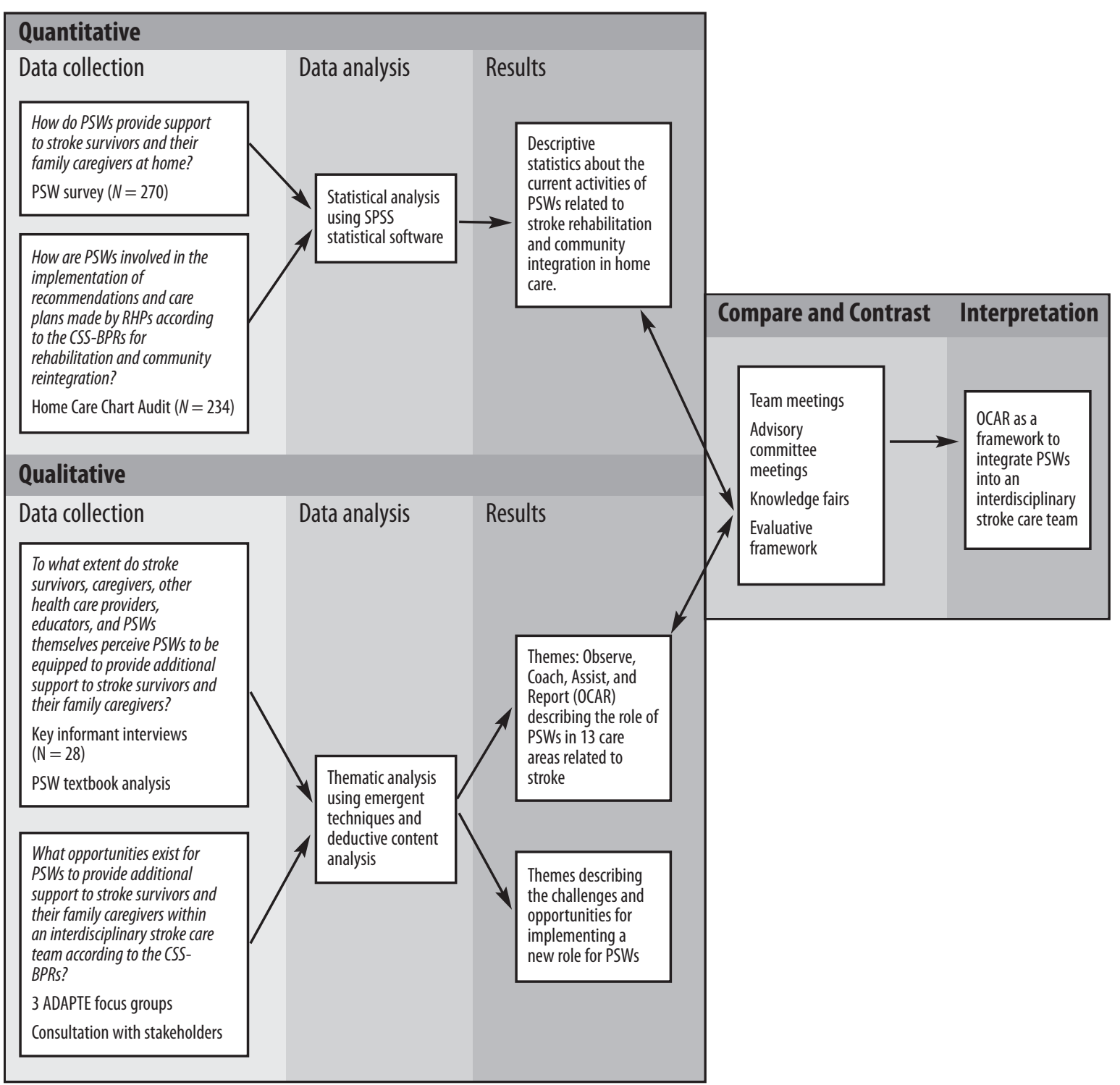

Figure 1. Concurrent triangulation mixed-methods design

\section{Sample and setting}

This research study was conducted in Ontario, which is the second largest province in Canada with a population of about 13.5 million [14]. Public funding for home care in Ontario is allocated by Community Care Access Centres (CCACs). CCAC care coordinators are responsible for assessing, coordinating, and allocating home care services, which may include nursing, rehabilitation, personal care, and/or home support services. Service provider organizations are contracted by the CCAC to deliver the services required by individuals in their homes [15]. Two of Ontario's largest service provider organizations participated in this research in two different geographic regions in southern Ontario, involving both urban and rural home care recipients and providers. 
5

Framework for Integrating Unregulated Healthcare Providers into Interdisciplinary Healthcare Teams

Giosa, Holyoke, Bender, Tudge, \& Gifford

Journal of Research in Interprofessional Practice and Education

Vol. 5.2

October 2015
Quantitative data collection and analysis

How do PSWs provide support to stroke survivors and their family caregivers at home?

A paper-based survey was developed to explore PSW s' perceived involvement in providing best-practice stroke care, including care activities that may go undocumented, as well as their preparedness, training, and ideas about resources and training that could enhance their role. The survey was based on an online environmental scan of PSW involvement in stroke care in Ontario. Prior to broad-scale administration of the survey, it was piloted with 28 PSWs to get their feedback on the length, ease of understanding, and content of the questions. The survey was then modified based on PSW comments and administered at staff meetings to PSWs $(N=270)$ working in the two home care organizations involved in the study in two geographic locations in southern Ontario. Data were entered into SPSS statistical software [16] for analysis; a random sample of $5 \%$ of surveys (14 surveys) were entered twice to check data entry accuracy and showed an acceptable, low error rate of $0.89 \%$. Data were analyzed and summarized as descriptive statistics.

How are PSWs involved in the implementation of recommendations and care plans made by Registered Health Professionals according to the CSS-BPRs for rehabilitation and community reintegration?

Home care charts $(N=234)$ were audited by two researchers (DB and ST) to explore documented activities related to PSWs' implementation of stroke care plans in home care. Paper and electronic charts were accessed for all clients who had a) received personal support services from either of the two home care organizations involved in the study within the 15-month period prior to the audit, b) had a stroke-related diagnosis, and c) were referred for PSW services in one of two geographic areas in southern Ontario. A paper-based chart audit tool was developed and used by the researchers for the consistent collection of basic demographic data as well as data related to formal care plans, care goals set by the home care funder, lists of tasks and activities assigned to PSWs by their supervisors, and notes recorded by PSWs or other healthcare providers about care for each client. Data were entered into SPSS statistical software [16]; a random sample of $10 \%$ of chart audit data (from 23 charts) were entered twice to check data entry accuracy and showed an acceptable, low error rate of $0.2 \%$. Data were analyzed and summarized as descriptive statistics.

\section{Qualitative data collection and analysis}

To what extent do stroke survivors, caregivers, healthcare providers, educators, and PSWs themselves perceive PSWs to be equipped to provide additional support to stroke survivors and their family caregivers?

Two researchers (DB and ST) conducted semi-structured key informant interviews $(N=28)$ to explore perspectives of PSW involvement in home-based stroke care. This included a random sample of PSWs who indicated an interest in participating in an interview when they completed the PSW survey. Interviews were also conducted with 
6

Framework for Integrating Unregulated Healthcare Providers into Interdisciplinary Healthcare Teams

Giosa, Holyoke, Bender, Tudge, \& Gifford

Journal of Research in Interprofessional Practice and Education

Vol. 5.2

October 2015 rehabilitation therapists, personal support supervisors (PSSs), and CCAC care coordinators who were identified by their supervisors and provided consent to be contacted by the researchers. A subset of stroke survivors whose charts were audited, as well as their family caregivers, provided their consent to be contacted by the researchers to participate in an interview. All participants provided written consent before being interviewed. The research team developed a unique interview guide to prompt each participant group to share their experiences being cared for by, working with, or working as PSWs, as well as their ideas for how PSWs could further contribute to best-practice stroke care. All interviews were audio-recorded and transcribed verbatim. Two standard textbooks, one older [17] and one newer [18], used in personal support training programs in Ontario, were also reviewed to gain an understanding of the evolving breadth and depth of education, information, and knowledge PSWs receive in their education. Semi-structured interview transcripts were analyzed using emergent techniques for thematic analysis [19]. An initial coding of emerging ideas, patterns, and interesting concepts followed a line-by-line reading of the data. These codes were then grouped into themes describing the potential role of PSWs in supporting evidence-based stroke rehabilitation and community reintegration. These emergent themes were then used as a priori themes to guide the deductive qualitative content analysis of the PSW textbooks [20,21].

What opportunities exist for PSWs to provide additional support to stroke survivors and their family caregivers within an interdisciplinary stroke care team according to the Canadian Stroke Strategy-Best Practice Recommendations (CSS-BPRs)?

As the CSS-BPRs were written to guide the activities of regulated healthcare providers and not explicitly to direct PSW care, the best practice sub-team applied a modified ADAPTE process [22] to adapt the CSS-BPRs to the PSW role in order to explore how PSWs could provide additional evidence-based support to stroke survivors and their family caregivers at home. The ADAPTE process is a three phase, evidencebased approach for adapting clinical best practice guidelines to new contexts [22]. The first phase of the ADAPTE process, known as the set-up phase, involved organizing an interdisciplinary best-practice sub-team to undertake the adaptation. This subteam consisted of a PSW, RN, PT, OT, SLP, and two researchers (JG and PH) from the study research team. Three half-day sub-team meetings were then scheduled and organized to carry out the adaptation phase [22] of the ADAPTE process. The researchers (JG and $\mathrm{PH}$ ) facilitated all three sub-team meetings as focus groups. In the first sub-team meeting, participants reviewed the full CSS-BPR document to develop a screening strategy. At the end of day one, the sub-team reached consensus that they would screen the CSS-BPRs related to 13 relevant stroke care areas in order to identify PSW activities that would trigger and support the implementation and/or maintenance of a CSS-BPR when working in an interdisciplinary care team (Table 1). Days two and three of the sub-team meetings involved facilitated interdisciplinary discussions to screen the CSS-BPRs using the developed strategy in order to identify relevant PSW activities to support evidence-based stroke care. Researchers (JG and PH) 
7

Framework for Integrating Unregulated Healthcare Providers into Interdisciplinary Healthcare Teams

Giosa, Holyoke, Bender, Tudge, \& Gifford
Journal of Research in Interprofessional Practice and Education

Vol. 5.2

October 2015 took detailed notes to document the discussions. Following the adaptation phase, the two researchers (JG and $\mathrm{PH}$ ) thematically analyzed the sub-team meeting notes independently using emergent coding techniques [19] to categorize and further refine the PSW activities to support evidence-based stroke care into themes. The researchers then came together to discuss, merge, and share their themes with the best practice sub-team and to create a consensus draft of themes and descriptions of PSW activities in each of the 13 client care areas. In the final phase of the ADAPTE process, known as the finalization phase [22], three of the consensus draft charts of PSW activities to support the CSS-BPRs were posted online for broad stake-

Table 1. Areas of stroke rehabilitation and community reintegration

\begin{tabular}{|l|}
\hline Swallowing \\
\hline Mental health and behaviour change \\
\hline Home safety and falls prevention \\
\hline Mobility, positioning, and transfers \\
\hline Public awareness \\
\hline Activities of daily living \\
\hline Independent activities of daily living and social reintegration \\
\hline Lifestyle and risk factor management \\
\hline Communication \\
\hline Client and caregiver support \\
\hline Pain management \\
\hline Cognition and perception \\
\hline Elimination and skin integrity \\
\hline
\end{tabular}
holder consultation (bolded in Table 1). These consultation documents were also distributed through 50 targeted emails to professional groups, regulatory bodies, academics, home care associations, and frontline providers to obtain feedback.

\section{Converging quantitative and qualitative data}

Using an integrated knowledge translation approach (iKT), researchers engaged in ongoing and iterative discussions during monthly team meetings and quarterly advisory committee meetings about how to bring together qualitative and quantitative data to develop an overall interpretation of the role of PSWs on an interdisciplinary stroke care team. An evaluative framework was developed to track similar findings between data sources about the role of PSWs in interdisciplinary stroke care. Following completion of the analysis of each individual data source, researchers met to compare and contrast the findings and fill out the evaluative framework with the most relevant data. Once the evaluative framework was completely filled out, researchers grouped similar data from multiple data sources into themes describing an enhanced role for PSWs in interdisciplinary stroke care (Table 2). Three interactive knowledge fairs were held in three southern Ontario cities to share and confirm the themes and supporting qualitative and quantitative data describing an enhanced role for PSWs in interdisciplinary stroke care with stakeholders $(N=112)$ and to gain ideas for action in policy, practice, training, and research that would promote the application of the findings. 


\section{Table 2. Evaluative framework for converging quantitative and qualitative data}

Framework for Integrating

Unregulated

Healthcare

Providers into Interdisciplinary Healthcare Teams

Giosa, Holyoke, Bender, Tudge, \& Gifford

Journal of Research in Interprofessional Practice and Education

Vol. 5.2

October 2015

\begin{tabular}{|c|c|c|c|c|c|}
\hline Themes & $\begin{array}{l}\text { Examples of activ- } \\
\text { ities aligned with } \\
\text { CSS-BPRs from } \\
\text { ADAPTE process }\end{array}$ & $\begin{array}{l}\text { Chart } \\
\text { audit }\end{array}$ & PSW survey & $\begin{array}{l}\text { Key informant inter- } \\
\text { views }\end{array}$ & PSW textbook analysis \\
\hline Observe & $\begin{array}{l}\text { For home safety and } \\
\text { falls prevention: iden- } \\
\text { tify safety hazards in } \\
\text { the home such as } \\
\text { scatter rugs, sharp } \\
\text { objects, and exposed } \\
\text { cords. }\end{array}$ & $\begin{array}{l}\text { A PSW note: } \\
\text { "Not aware of } \\
\text { things } \\
\text { around him. } \\
\text { Very deep } \\
\text { breathing. } \\
\text { Had eye con- } \\
\text { tact by the } \\
\text { time para- } \\
\text { medics came. } \\
\text { Sent to the } \\
\text { hospital." }\end{array}$ & $\begin{array}{l}\text { Ninety percent } \\
\text { of respondents } \\
\text { able to recog- } \\
\text { nize the signs } \\
\text { and symptoms } \\
\text { of stroke. }\end{array}$ & $\begin{array}{l}\text { A PSW discussed the obser- } \\
\text { vations they make about } \\
\text { stroke survivors: "... they } \\
\text { may not be able to, um, no } \\
\text { longer independently } \\
\text { dress themselves, feed } \\
\text { themselves, you know, just } \\
\text { everyday challenges, even } \\
\text { with walking and ambulat- } \\
\text { ing, you know. So, you } \\
\text { know, are they going to } \\
\text { need physio or rehab?" }\end{array}$ & $\begin{array}{l}\text { "You make many observations } \\
\text { as you give care and talk to } \\
\text { patients and residents. } \\
\text { Observation is using the } \\
\text { senses of sight, hearing, } \\
\text { touch, and smell to collect } \\
\text { information ... You should } \\
\text { make notes of your observa- } \\
\text { tions ..." [17] (p. 51) }\end{array}$ \\
\hline Coach & $\begin{array}{l}\text { For communication: } \\
\text { reinforce success and } \\
\text { provide encourage- } \\
\text { ment to the client } \\
\text { and/or caregivers to } \\
\text { continue working } \\
\text { toward improving } \\
\text { their communication. }\end{array}$ & $\begin{array}{l}\text { A PSW note: } \\
\text { "Client is } \\
\text { doing well, } \\
\text { going to } \\
\text { supervise } \\
\text { while she } \\
\text { folds some } \\
\text { clothes to } \\
\text { help with her } \\
\text { occupational } \\
\text { therapy." }\end{array}$ & $\begin{array}{l}\text { Ninety percent } \\
\text { of respondents } \\
\text { promoted the } \\
\text { safe use of assis- } \\
\text { tive devices such } \\
\text { as walkers and } \\
\text { hearing aids. }\end{array}$ & $\begin{array}{l}\text { A PSW discussed support- } \\
\text { ing caregivers: "Just } \\
\text { encouraging [caregivers] } \\
\text { and talking to them. 'Do } \\
\text { you want to talk about } \\
\text { this?'If they want to ask } \\
\text { me questions I'Il answer } \\
\text { their questions to the best } \\
\text { of my ability or forward } \\
\text { them to whoever can. If } \\
\text { they're just having a bad } \\
\text { day and they need some- } \\
\text { body to listen to them, } \\
\text { that's fine." }\end{array}$ & $\begin{array}{l}\text { "One of your responsibilities } \\
\text { as a support worker is to } \\
\text { explain procedures and tasks } \\
\text { to clients, as some procedures } \\
\text { may be unfamiliar or frighten- } \\
\text { ing to them ... You may help } \\
\text { clients practice tasks they } \\
\text { have been taught by health- } \\
\text { care professionals...." [18] (p. } \\
\text { 194) }\end{array}$ \\
\hline Assist & $\begin{array}{l}\text { For mobility, position- } \\
\text { ing and transfers: } \\
\text { assist the client } \\
\text { and/or caregiver(s) to } \\
\text { integrate adaptive } \\
\text { techniques recom- } \\
\text { mended by a regu- } \\
\text { lated health } \\
\text { professional into daily } \\
\text { activities and assist } \\
\text { them to perform } \\
\text { these activities as } \\
\text { safely and independ- } \\
\text { ently as possible. }\end{array}$ & $\begin{array}{l}\text { Eighty-eight } \\
\text { percent of } \\
\text { charts indi- } \\
\text { cated PSWs } \\
\text { assist with } \\
\text { bathing and } \\
\text { showering. }\end{array}$ & $\begin{array}{l}\text { Respondents } \\
\text { indicated that } \\
\text { they helped } \\
\text { clients "always" } \\
\text { or "a lot" with } \\
\text { proper position- } \\
\text { ing (76\%). }\end{array}$ & $\begin{array}{l}\text { A caregiver discussed PSW } \\
\text { assistance: “... I couldn't } \\
\text { have done all that stuff } \\
\text { that [the PSWs] did ... } \\
\text { day one you're dealing } \\
\text { with all of the bodily func- } \\
\text { tions, all of the physical } \\
\text { stuff ... Without them it } \\
\text { would have been ... } \\
\text { extremely difficult." }\end{array}$ & $\begin{array}{l}\text { "The professionals on the } \\
\text { rehabilitation team choose } \\
\text { the therapy and training } \\
\text { needed to meet the client's } \\
\text { goals. The client is taught } \\
\text { how to improve a skill or how } \\
\text { to perform a task and prac- } \\
\text { tices what was learned either } \\
\text { independently or with a care- } \\
\text { giver or a family member. You } \\
\text { may be required to help } \\
\text { clients practice skills or tasks." } \\
\text { [18] (p. 760) }\end{array}$ \\
\hline Report & $\begin{array}{l}\text { For cognition, mood, } \\
\text { and behaviour } \\
\text { change: report } \\
\text { progress and/or lack } \\
\text { of expected progress } \\
\text { in managing mood } \\
\text { and behaviours to the } \\
\text { PSW supervisor and } \\
\text { other members of the } \\
\text { client's healthcare } \\
\text { team. }\end{array}$ & $\begin{array}{l}\text { A PSW note: } \\
\text { "[Client] is } \\
\text { interested in } \\
\text { doing her } \\
\text { own care, } \\
\text { was already } \\
\text { starting to } \\
\text { get ready for } \\
\text { bed." }\end{array}$ & $\begin{array}{l}\text { Respondents } \\
\text { predominantly } \\
\text { provide informa- } \\
\text { tion about their } \\
\text { stroke clients to } \\
\text { their supervisors } \\
\text { (47\%) and less } \\
\text { than } 10 \% \text { of the } \\
\text { respondents } \\
\text { indicated they } \\
\text { provide updates } \\
\text { "always" or"a } \\
\text { lot" to PTs, OTs, } \\
\text { SLPs, or care } \\
\text { coordinators. }\end{array}$ & $\begin{array}{l}\text { A PSW supervisor indi- } \\
\text { cated: "... So not only ... } \\
\text { are [they] going in for the } \\
\text { specific thing that I asked } \\
\text { for, hopefully that they're } \\
\text { assessing the whole client } \\
\text { atmosphere, living } \\
\text { cond[ition] ... I'm only as } \\
\text { good as the information I } \\
\text { get [from the PSW]." }\end{array}$ & $\begin{array}{l}\text { "Sometimes you are the first } \\
\text { to notice a change in a client's } \\
\text { condition, and you observe } \\
\text { the client's preferences and } \\
\text { reactions to interventions. You } \\
\text { are expected to make careful } \\
\text { and accurate reports of these } \\
\text { observations, which will be } \\
\text { used in the care planning } \\
\text { process ... Objective data ... } \\
\text { subjective data ...." [18] } \\
\text { (p. 103) }\end{array}$ \\
\hline
\end{tabular}


9

Framework for Integrating Unregulated Healthcare Providers into Interdisciplinary Healthcare Teams

Giosa, Holyoke, Bender, Tudge, \& Gifford
Journal of Research in Interprofessional Practice and Education

Vol. 5.2

October 2015

\section{Results}

\section{Demographics}

The demographic profile of clients whose charts were reviewed is in Table 3. Eighty-two percent $(N=192)$ of clients whose charts were reviewed were actively receiving personal support services at the time of the audit, and $18 \%(N=42)$ had been discharged from service in the 15-month period prior to the audit. The mean number of hours of governmentfunded PSW services received by these clients was 8.3 hours per week.

The profiles of the PSWs who participated in the surveys $(N=270)$ are contained in Table 4 . When asked how many stroke clients they cared for in the previous three years, half the survey respondents (50\%) identified providing care to zero to five clients and $9 \%$ identified caring for more than 15 stroke clients. Ninety-two percent of surveyed PSWs expressed that they had confidence in their knowledge of the risks of stroke and $90 \%$ had confidence in their ability to recognize the signs and symptoms of stroke. Most of the PSWs surveyed received their PSW training from a community college.

Four clients, two caregivers, and 22
Table 3. Profile of clients whose chart was reviewed

\begin{tabular}{|c|c|c|}
\hline & & $\begin{array}{l}\text { Chart Audit } \\
(N=234)\end{array}$ \\
\hline Gender & $\begin{array}{l}\text { Women } \\
\text { Men }\end{array}$ & $\begin{array}{l}N=13758.5 \% \\
N=9741.5 \%\end{array}$ \\
\hline Age & $\begin{array}{l}\text { Under } 40 \\
41-64 \\
65-84 \\
85 \text { and over } \\
\text { Age not recorded }\end{array}$ & $\begin{array}{l}0.8 \% \\
12.0 \% \\
49.1 \% \\
37.6 \% \\
0.4 \%\end{array}$ \\
\hline $\begin{array}{l}\text { Date of } \\
\text { stroke }\end{array}$ & $\begin{array}{l}<3 \text { months ago } \\
>3 \text { months ago } \\
\text { Both } \\
\text { Unknown }\end{array}$ & $\begin{array}{l}53.9 \% \\
24.8 \% \\
9.4 \% \\
12.0 \%\end{array}$ \\
\hline $\begin{array}{l}\text { Secondary } \\
\text { diagnoses }\end{array}$ & $\begin{array}{l}\text { Hypertension } \\
\text { Cardiovascular disease } \\
\text { Diabetes } \\
\text { Aphasia } \\
\text { Hyperlipidemia } \\
\text { Dysphagia } \\
\text { Other }\end{array}$ & $\begin{array}{l}44.0 \% \\
32.5 \% \\
25.6 \% \\
3.8 \% \\
2.6 \% \\
1.7 \% \\
8.2 \%\end{array}$ \\
\hline
\end{tabular}
healthcare providers (three care coordinators, five therapists, seven PSSs, and seven PSWs) were interviewed. All four clients interviewed also had their chart audited. Both caregivers interviewed were spouses and lived in the same household as the clients. All healthcare providers interviewed had been working in home care for more than one year.

The participants in the knowledge fairs were varied, including PSWs, students training to become PSWs, nurses, rehabilitation therapists, healthcare managers, and researchers.

Themes describing an enhanced role for PSWs working in a team Four themes describing an enhanced role for PSWs in evidence-based rehabilitation and community re-integration relevant to 13 areas of stroke care emerged from the data. These themes take into account both what PSWs document and perceive as part of their role in supporting stroke survivors and family caregivers at home (quantitative data), as well as interdisciplinary opinions and ideas about how PSWs can provide additional support to trigger and support the implementation and/or main- 
10

Framework for Integrating Unregulated Healthcare Providers into Interdisciplinary Healthcare Teams

Giosa, Holyoke, Bender, Tudge, \& Gifford
Journal of Research in Interprofessional Practice and Education

Vol. 5.2

October 2015
Table 4. Profile of PSWs who responded to the survey

\begin{tabular}{|c|c|c|c|}
\hline & & & \\
\hline & & $N$ & $\%$ \\
\hline $\begin{array}{l}\text { Length of time work- } \\
\text { ing as a PSW }\end{array}$ & $\begin{array}{l}\text { Less than } 1 \text { year } \\
1 \text { to } 5 \text { years } \\
6 \text { to } 10 \text { years } \\
\text { More than } 10 \text { years }\end{array}$ & $\begin{array}{c}35 \\
84 \\
49 \\
101\end{array}$ & $\begin{array}{l}13 \% \\
31 \% \\
18 \% \\
38 \%\end{array}$ \\
\hline $\begin{array}{l}\text { Length of time work- } \\
\text { ing as a PSW in home } \\
\text { care }\end{array}$ & $\begin{array}{l}\text { Less than } 1 \text { year } \\
1 \text { to } 5 \text { years } \\
6 \text { to } 10 \text { years } \\
\text { More than } 10 \text { years }\end{array}$ & $\begin{array}{l}44 \\
86 \\
47 \\
92\end{array}$ & $\begin{array}{l}16 \% \\
32 \% \\
18 \% \\
34 \%\end{array}$ \\
\hline $\begin{array}{l}\text { Type of agency PSW } \\
\text { training was received }\end{array}$ & $\begin{array}{l}\text { Community college } \\
\text { Board of education } \\
\text { Private vocational school } \\
\text { Not-for-profit organization } \\
\text { Employer-based training } \\
\text { Other }\end{array}$ & $\begin{array}{c}160 \\
34 \\
40 \\
11 \\
55 \\
7\end{array}$ & $\begin{array}{c}61 \% \\
13 \% \\
15 \% \\
4 \% \\
21 \% \\
3 \%\end{array}$ \\
\hline
\end{tabular}

tenance of CSS-BPRs (qualitative data). A brief description of each theme appears below, followed by a more detailed summary of the evidence supporting each theme.

Theme 1: Observe-A PSW pays careful attention and makes inquiries to notice, learn, or perceive significant issues about the client's care. Theme 2: Coach-A PSW explains and demonstrates to the client and caregiver how to carry out an activity for the client's care and offers encouragement.

Theme 3: Assist-A PSW provides support to a client and caregiver to complete a care-related task through physical help or verbal cueing.

Theme 4: Report-A PSW provides spoken or written accounts to other members of the client's healthcare team of an important observation, action, or change regarding the client's care.

\section{Theme 1: Observe}

Data revealed that PSW s are the "eyes" of an interdisciplinary stroke care team in the home, observing the client's situation, relationships, and home environment, as well as changes in the client's condition. The ADAPTE process identified important aspects of care PSWs could observe related to 13 areas of stroke care addressed by the CSSBPRs. For example, with regard to home safety and falls prevention, PSWs could observe safety hazards in the home including scatter rugs, sharp objects, and exposed electrical cords. Chart audits revealed clinical notes of observations made by PSWs about stroke survivors. For example, one PSW commented on a stroke survivor's awareness, breathing, and eye contact in an emergency situation. The PSW survey also supported the PSW role as observer. For example, many PSWs (90\%) reported confidence in their ability to recognize stroke signs and symptoms. Interviews indi- 
11

Framework for Integrating Unregulated Healthcare Providers into Interdisciplinary Healthcare Teams

Giosa, Holyoke, Bender, Tudge, \& Gifford

Journal of Research in Interprofessional Practice and Education

Vol. 5.2

October 2015 cated that PSWs often observe important aspects of a client's care. One PSW discussed these observations: “... they may not be able to ... independently dress themselves, feed themselves ... just everyday challenges, even with walking and ambulating ... are they going to need physio[therapy] or rehab...?" The textbook analysis shows emphasis on the factors PSWs can be looking for and monitoring on behalf of the members of the interdisciplinary care team, who usually spend less time with the client, and encourages PSWs to take notes of their observations.

\section{Theme 2: Coach}

According to the data, PSWs can play an important role in interdisciplinary stroke care by verbally coaching clients and families in their rehabilitation journey. The ADAPTE process identified important areas of coaching related to 13 areas of stroke care addressed by the CSS-BPRs. For example, PSWs can coach clients in their communication by reinforcing success and encouraging clients to continue working on communication strategies implemented by RHPs. Chart audits revealed clinical notes from PSWs related to their coaching efforts. For example, one PSW documented: "Client is doing well, going to supervise while she folds some clothes to help with her occupational therapy." Further, the surveys revealed that PSWs promoted the safe use of assistive devices, with $90 \%$ of respondents reporting that the activities they performed "always" or "a lot" of the time were related to ensuring homes were safe and encouraging the use of supportive equipment such as walkers and hearing aids. Another aspect of the coaching role was providing encouragement, information, and emotional support to stroke survivors and their families. In an interview, one PSW described this as follows: "Just encouraging [caregivers] and talking to them. 'Do you want to talk about this?' If they want to ask me questions, I'll answer their questions to the best of my ability or forward them to whoever can. If they're just having a bad day and they need somebody to listen to them, that's fine." The textbook analysis reveals emphasis on explaining procedures to clients and families and encouraging them to complete their care activities.

\section{Theme 3: Assist}

The data revealed that PSWs can make significant contributions to interdisciplinary stroke care by assisting clients and families in implementing their rehabilitation and community reintegration care plans. The ADAPTE process revealed a variety of care activities that PSWs can assist stroke survivors with related to 13 areas of stroke care. For example, PSWs can help clients and their caregivers integrate adaptive techniques for completing ADLs and IADLs into their daily routine. The chart audit revealed that the areas of care PSWs most frequently assist clients with are ADLs and IADLs. For example, $88 \%$ of charts indicated PSWs assist with bathing and showering. PSW surveys further support the Assist theme, with $76 \%$ of respondents indicating they help clients "always" or "a lot" with proper positioning. This was reinforced through the interviews, as one caregiver reflected on the assistance provided to his family member, "I couldn't have done all that stuff that [the PSWs] did ... day one you're dealing with all of the bodily functions, all of the physical stuff .... Without 
12

Framework for Integrating Unregulated Healthcare Providers into Interdisciplinary Healthcare Teams

Giosa, Holyoke, Bender, Tudge, \& Gifford
Journal of Research in Interprofessional Practice and Education

Vol. 5.2

October 2015 them it would have been ... extremely difficult." The textbook analysis reveals instructions for PSWs to assist clients in the implementation and practicing of the strategies taught to them by RHPs.

\section{Theme 4: Report}

The data indicated that within an interdisciplinary stroke care team, PSWs can play a vital role in maintaining a consistent information flow about a stroke survivor's rehabilitation through reporting. Reporting may include direct communication with the other care team members and/or documentation of pertinent client information. The ADAPTE process identified aspects of care in 13 areas related to strokes that PSWs could document when providing care to stroke survivors. Chart reviews revealed PSW documentation related to progress and lack of progress made by clients. One PSW note stated: "[Client] is interested in doing her own care, was already starting to get ready for bed." PSW surveys confirmed the PSW role in reporting information, with $48 \%$ of respondents consistently reporting information to their supervisor. However, less than $10 \%$ of respondents indicated they provide updates "always" or "a lot" to PTs, OTs, SLPs, or care coordinators. Interviews indicated that RHPs appreciate receiving information from PSWs. For example, one personal support supervisor stated:

Basically if the client is not managing very well and the PSW lets me know that they think this client now is having a hard time getting off the toilet, really needs a raised toilet seat, then I will call the case manager and say: "This is what's happening. Can you send in an OT to see about bed transfers or toilet transfers or any other assistive devices?" So not only ... are [they] going in for the specific thing that I asked for, hopefully they're assessing the whole client atmosphere, living cond[ition] ... I'm only as good as the information I get [from the PSW].

Finally, the textbook analysis reveals in-depth instructions for PSWs to make detailed and accurate reports of their observations about a client.

\section{Anticipated challenges in expanding the PSW role}

Three additional themes emerged from the qualitative data analysis around anticipated challenges in the expansion of the PSW role on an interdisciplinary team within the current context of Ontario home care. A description of each theme follows.

\section{Lack of awareness of what PSWs are qualified and trained to do}

PSWs' qualifications and training were not well known to study participants due to the lack of standardization in PSW education, as PSWs are unregulated healthcare providers. RHP participants in this study were unaware of PSWs' education as it relates to stroke care, as stated by a physiotherapist interviewed for the study, "I don't know what amount of education they have formally or on-the-job training." Study participants also shared that there is variability in expectations among the care team 
Framework for Integrating Unregulated Healthcare Providers into Interdisciplinary Healthcare Teams

Giosa, Holyoke, Bender, Tudge, \& Gifford

Journal of Research in Interprofessional Practice and Education

Vol. 5.2

October 2015 and clients/families about what PSWs should and can reasonably do to help stroke survivors and family members at home. One PSW said, "They [family members] think maybe we should be doing more than what our limitations allow ... we tell them we're personal support workers but they still call us nurses. I say 'No, I'm not a nurse. I didn't go to school for nursing. This is what I do and this is what I'm allowed to do."

\section{The PSW role on interdisciplinary healthcare teams is not well-defined or understood}

The inclusion and role of PSWs on interdisciplinary care teams was not well-defined or understood by study participants. Since RHP members of interdisciplinary care teams are not typically in a client home at the same time as PSWs, they did not tend to know what PSWs were doing to support clients. As one SLP stated: "So very often it's kind of hit or miss if I even see a PSW and I'm given information second hand ... so I would love to be able to have a forum or a method in the community of building capacity in that way." Study participants had a hard time envisioning how PSWs could participate as active members of an interdisciplinary healthcare team. When asked how PSWs could work with RHPs to support the implementation of CSSBPRs, one care coordinator stated: “... I'm not sure if they've [PSWs] had any kind of specialized education about stroke best practices. You know, I think they'd be able to help with, you know, with their personal care, um, you know, the ADLs at home but, uh, I'm not sure."

\section{Health system policies, procedures, and processes impede interdisciplinary collaboration}

Health system policies, procedures, and processes were identified as impediments to the two-way sharing of information among team members. Interviewees identified home care charting procedures as challenging, as each discipline maintains their own documentation system that is, for the most part, not accessible to PSWs. One PSS stated that it would be beneficial "if they [the healthcare team] can communicate through a log book, some way to let them know further what's going on. But it's very, I guess, segregated." Communication is also further hindered, as PSWs are not always present in the home at the same time as other providers. One PSW stated, "Under normal circumstances we don't see any other healthcare professionals." Another challenge to enhancing the PSW role might be that PSWs have limited opportunities to be directly trained by rehabilitation therapists. PSS mediate PSW training on rehabilitation activities. For example, one physiotherapist stated:

If I want them to do something then ... I ask the supervisor. We set up a session and I try and get them or the supervisor tries to get as many of the personal support workers involved in that client's care to be there when I do it. I explain everything, show them, demonstrate, ask them to show me how they do it. I write it all down, leave instructions in the home ... and then I usually do a follow up after to see that they've actually learned. 
Framework for Integrating Unregulated Healthcare Providers into Interdisciplinary Healthcare Teams

Giosa, Holyoke, Bender, Tudge, \& Gifford

Journal of Research in Interprofessional Practice and Education

Vol. 5.2

October 2015

\section{Journal of Research in Interprofessional Practice and Education}

High turnover rates were also identified by occupational therapists as further limiting information sharing and training: "And also the other problem is they're [the clients] trying to get care but they're always changing the workers."

\section{Discussion}

PSWs are already making significant contributions to the care of stroke survivors and their family caregivers at home and in the community-as evidenced by both the personal care activities that are documented and the support they provide that goes undocumented. What is missing is PSWs' explicit inclusion and linkage to other healthcare providers involved in interdisciplinary stroke care teams. This research suggests that PSWs have a key but underutilized role in enhancing intra-team communication, information sharing, and continuity of evidence-based care to improve the integration of stroke care and the experiences of stroke survivors and family caregivers.

The Observe, Coach, Assist, and Report (OCAR) themes define four important areas for enhancing the role of PSWs as key members of interdisciplinary stroke care teams so they may trigger or support the implementation and/or maintenance of CSS-BPRs. We believe that applying the OCAR themes as a framework within existing stroke care practices has the potential to enhance point-of-care integration of interdisciplinary stroke care.

Our research revealed one other Canadian framework for describing the PSW role. The "Framework of Practice for Community Health Workers \& Resident Care Attendants" [23] from the British Columbia Ministry of Health serves to describe the key functions of unregulated care providers on interdisciplinary teams. In this framework, the following five functions of unregulated healthcare providers are described:

Use a problem-solving approach to provide assistance and support that promotes the well-being of clients, residents, families, and other team members;

Communicate effectively with clients, residents, families, and other team members;

Contribute to promoting and maintaining a safe and healthy environment;

Perform a job in an ethical, responsible, and accountable manner, maintaining competent practice; and

Support the dignity, uniqueness, and fair treatment of clients, residents, their families, and others [23].

Both the OCAR themes and the framework from the British Columbia Ministry of Health focus on the overall role of PSWs within a holistic approach to care and collaboration with other healthcare providers. The OCAR framework goes further in that it describes the specific types of activities PSWs can perform that will trigger and support the implementation and/or maintenance of evidence-based care by RHPs.

The Ontario Personal Support Worker Association (OPSWA) is launching a Personal Care Best Practice Guidelines (BPG) Program that focuses on standardiz- 
15

Framework for Integrating Unregulated Healthcare Providers into Interdisciplinary Healthcare Teams

Giosa, Holyoke, Bender, Tudge, \& Gifford

Journal of Research in Interprofessional Practice and Education

Vol. 5.2

October 2015 ing typical PSW care tasks, such as bathing, toileting, and oral hygiene, with the goal of improving PSW practice [24]. This is a different approach than our study findings suggest. The OCAR themes are not meant to add more rigidity and structure to the personal care tasks that PSWs already perform, but, instead, guide interdisciplinary teams on how to optimize the frequent and consistent interactions between PSWs and stroke survivors through these personal care activities. This approach can enable PSW s to observe and report important information about clients' care, coach clients and families in ways that will reinforce RHP recommendations, and ensure the assistance they provide in their personal care tasks is consistent with RHP rehabilitation strategies. This will contribute to all care team members working toward common goals using evidence-based strategies. Standardizing individual PSW care tasks could potentially be complementary to the application of the OCAR themes within interdisciplinary stroke care; however, the data from this study do not suggest that standardization is a prerequisite for the OCAR themes to be useful at a team level.

Our results suggest that there is a general lack of awareness of the PSW role in home care, not only by other healthcare providers but also by clients, families, and other community stakeholders. A recent study by Estabrooks and colleagues [25] similarly highlighted that the PSW workforce in LTC is poorly understood. One key issue is that there is a dearth of research that defines PSWs as key members of interdisciplinary care teams when testing new interventions and models of care. For example, we reviewed 146 references used to support the development of the CSS-BPRs in the 13 care areas we examined, and found limited inclusion and inconsistent consideration of unregulated providers, including "family support workers," "support staff," "nursing aides," and "care assistants." There is also an absence of practice standards from the professional colleges and associations to guide the interaction between PSWs and rehabilitation therapists, which contributes to the limited understanding of their role. Indeed, many college practice standards explicitly exclude unregulated care providers such as PSWs in their guidance about relationships with assistants [26-28].

From our interviews with PSSs, nurses appear to have a clearer understanding of the PSWs' role and scope of practice than other members of the healthcare team. This may be because nursing colleges provide clear guidelines for working with unregulated health professionals, and they have opportunities to communicate directly with one another. In our review of the CSS-BPRs, it was learned that PSWs are rarely in the home at the same time as other healthcare providers, and this lack of face-to-face interaction prevents other healthcare providers from understanding their role. It was also suggested in the review of CSS-BPRs that RHPs feel very strongly about their professional boundaries and accountabilities and they may feel threatened by a perceived expansion of unregulated care providers' scope of practice.

While a lack of awareness of the PSW role might inhibit collaboration among members of a stroke care team, there is evidence to suggest that regulated and unregulated healthcare providers can effectively work together when there is an explicit effort made to facilitate meaningful interactions. For example, in a recent study by Markle-Reid et al. [8], a specialized interprofessional team approach to stroke rehabilitation was compared to usual home and community care; the researchers 
16

Framework for Integrating Unregulated Healthcare Providers into Interdisciplinary Healthcare Teams

Giosa, Holyoke, Bender, Tudge, \& Gifford
Journal of Research in Interprofessional Practice and Education

Vol. 5.2

October 2015 reported clinically meaningful (but not statistically significant) improvements in physical and social functioning compared to the usual care group. The interprofessional team included a PT, OT, SLP, registered dietician, RN, social worker, and a PSW working together to provide comprehensive, collaborative, and evidence-based rehabilitation over a 12-month period; however, specific details about the interactions and how they were directly linked to the demonstrated outcomes were not described. The current study suggests that the OCAR themes may be helpful in articulating the types of interactions that healthcare providers should have to support stroke rehabilitation and community reintegration. Given the current lack of clarity on PSW qualifications and training, adopting a common framework for describing the PSW role might help to clarify some of this ambiguity and provide guidance for how unregulated and regulated healthcare providers can better work together.

Two-way communication and information sharing was identified as a challenge in the present study. There is evidence to support that incorporating PSWs as explicit members of interdisciplinary care teams fosters open and direct communication among team members, leading to better outcomes for home care clients. For example, the Central West CCAC in Ontario implemented a program called Home Independence Program (HIP) to improve restorative care for older adults. The HIP program actively engaged PSWs in care planning and delivery, including involvement in weekly care conferences with the other members of the healthcare team. This program led to positive outcomes for clients, including earlier discharge from service, increased mobility, reduced falls, decreased emergency department visits, and increased satisfaction [29]. Clear expectations and protocols were developed to guide the interactions among the interdisciplinary team members, which enabled the successful implementation of the HIP program in a region in which policies and procedures have traditionally impeded communication. Furthermore, providing the appropriate resources and structure to foster quality interprofessional relationships that include PSWs as explicit members of an interdisciplinary team have proven to predict more individualized care in the LTC setting [30]. The HIP program lends support for the applicability of the OCAR themes as they could similarly guide interdisciplinary interactions in the current home care context and potentially be applied in other sectors as well.

\section{Recommendations}

To address existing challenges to integrated stroke care and further test the application of the OCAR themes as a framework to guide interdisciplinary collaboration, the following recommendations are proposed:

Policy: Address structural issues that prevent PSWs from explicit inclusion on integrated stroke care teams. This could include revisions to communication processes and mechanisms that currently limit the sharing of information between PSWs and rehabilitation professionals, increased standardization of PSW education and training programs, and improved guidance from rehabilitation professional associations 
17

Framework for Integrating Unregulated Healthcare Providers into Interdisciplinary Healthcare Teams

Giosa, Holyoke, Bender, Tudge, \& Gifford
Journal of Research in Interprofessional Practice and Education

Vol. 5.2

October 2015

\section{Journal of Research in Interprofessional Practice and Education}

and colleges regarding how their members can work together with PSWs to provide healthcare.

Practice: Increase awareness of the important role PSWs play in stroke rehabilitation and community reintegration. The OCAR themes could be applied as a framework by RHPs within interdisciplinary stroke care teams to provide team members with a common language for explicitly defining the PSW role on the team during care planning to communicate about the care that is provided, and to identify the interactions between PSWs and other care team members required to enable PSWs to more actively contribute to collaborative evidence-informed care and the achievement of rehabilitation goals.

Training: Improve training of PSWs and rehabilitation professionals to enhance their ability to work together, including offering interdisciplinary education using diverse modalities (e.g., group sessions, online workshops) and involving rehabilitation professionals more in the direct training of PSWs to ensure they have the knowledge and skills required to support stroke rehabilitation and community reintegration.

Research: Test the OCAR themes as a framework for describing the PSW role in an interdisciplinary stroke team in one or more of the identified client care areas from the CSS-BPRs (Table 1) and in other clinical areas of care (e.g., end-of-life care).

\section{Limitations}

There are several limitations to this research. First, this work was descriptive in nature and therefore further testing is required regarding the applicability of the OCAR framework in practice. Based on feedback from a broad range of stakeholders, the findings appear meaningful within the current context of home care and will be useful to inform a rigorous pilot implementation of the framework. Additionally, this research focused on stroke survivors and their family caregivers in home and community care, limiting the applicability of the OCAR themes as a framework to guide the PSW role in interdisciplinary care in other sectors and patient populations. However, as the OCAR themes are focused on interactions between healthcare providers, and not on disease-specific clinical tasks, the possibility of testing the applicability of these themes in other settings, and with other types of patients, is warranted.

\section{Conclusion}

PSWs provide the majority of home care in Ontario, yet there is little clarity and awareness about their role as important members of an interdisciplinary care team. More structure is needed to increase the understanding among care team members 
18

Framework for Integrating Unregulated Healthcare Providers into Interdisciplinary Healthcare Teams

Giosa, Holyoke, Bender, Tudge, \& Gifford
Journal of Research in Interprofessional Practice and Education

Vol. 5.2

October 2015 about how they can work together to achieve more integrated, evidence-based home care. The OCAR themes are not meant to add more rigidity and structure around the specific personal care activities of unregulated care providers, but rather to help identify how interdisciplinary care teams can optimize the frequent and consistent interactions PSWs typically have with stroke survivors and their families so that all care team members are working toward common goals using evidence-based strategies. Interdisciplinary care teams could apply OCAR themes as a framework for defining the PSW contribution to the team for each individual stroke client. For example, RHPs could apply OCAR in the development of a customized care plan for each stroke survivor by identifying the specific activities PSWs can observe and report to others, and the role PSWs can play in coaching and assisting with evidence-based care recommendations by RHPs for rehabilitation and community reintegration. Accounting for PSW participation using the OCAR themes at the care planning stage has the potential to facilitate more integrated, coordinated, and continuous evidence-based stroke care. Integral to the application of the OCAR themes will be enhanced communication mechanisms to support information sharing among all members of the care team.

Future directions for this work will include testing the application of the OCAR themes as a framework to guide interdisciplinary collaboration with PSWs in home care, and potentially other healthcare settings, across the continuum of care that requires unregulated healthcare providers and RHPs to work together. By addressing the existing structural barriers to communication and collaboration, by increasing awareness of PSW care activities and their role, and by improving the training of PSW s and RHPs to more fully support them in working together, we will be able to move toward a more integrated, person-centred approach to care for home care clients and their families.

$\begin{array}{ll}\text { Abbreviations } \\ \text { CCAC } & \text { Community Care Access Centre } \\ \text { CSS-BPRs } & \text { Canadian Stroke Strategy best practice recommendations } \\ \text { HIP } & \text { Home Independence Program } \\ \text { IADL } & \text { Instrumental activities of daily living } \\ \text { iKT } & \text { Integrated knowledge translation approach } \\ \text { LTC } & \text { Long-term care } \\ \text { OCAR } & \text { Observe, Coach, Assist, and Report } \\ \text { OPSWA } & \text { Ontario Personal Support Worker Association } \\ \text { OT } & \text { Occupational therapist } \\ \text { PSS } & \text { Personal support supervisor } \\ \text { PSW } & \text { Personal support worker } \\ \text { PT } & \text { Physiotherapist } \\ \text { RHP } & \text { Regulated health professional } \\ \text { RN } & \text { Registered nurse } \\ \text { SLP } & \text { Speech language pathologist } \\ \text { SW } & \text { Social worker }\end{array}$


19

Framework for Integrating Unregulated Healthcare Providers into Interdisciplinary Healthcare Teams

Giosa, Holyoke, Bender, Tudge, \& Gifford

Journal of Research in Interprofessional Practice and Education

Vol. 5.2

October 2015

\section{References}

1. Association of Canadian Community Colleges (ACCC) \& Canadian Association of Continuing Care Educators (CACCE). (2012). Canadian educational standards for personal care providers: A reference guide. URL: http://www.cacce.ca/page17.html [June 11, 2012].

2. Home Care Ontario. (2014). Fact and figures - Publicly funded home care. Toronto, ON: Home Care Ontario. URL: http://www.homecareontario.ca/home-care-services/facts-figures/publiclyfunded homecare [January 26, 2015].

3. Pan-Canadian Planning Committee on Unregulated Health Workers. (2008). Valuing health-care team members: Working with unregulated health workers: A discussion paper. Ottawa, ON: Pan-Canadian Planning Committee on Unregulated Health Workers. URL: http://cna-aiic.ca/ /media/cna/page -content/pdf-en/19\%20-\%20uhw_valuing_2008_e.pdf [January 26, 2015].

4. Ontario Community Support Association. (2012). The Ontario personal support worker registry: Public report. North York, ON: Ontario Community Support Association. URL: http://www .crncc.ca/knowledge/related_reports/pdf/ontario-psw-registry-public-report-sep-2012.pdf [January 26, 2015].

5. Canadian Home Care Association. (2008). Portraits of home care in Canada. Mississauga, ON: Canadian Home Care Association. URL: http://www.cdnhomecare.ca/media.php?mid=1877 [January 26, 2015].

6. Kontos, Pia, Miller, Karen-Lee, \& Mitchell, Gail. (2010). Neglecting the importance of the decisionmaking and care regimes of personal support workers: A critique of standardization of care planning through the RAI/MDS. The Gerontologist, 50(3), 352-362.

7. Kaasalainen, Sharon, Brazil, Kevin, \& Kelley, Mary L. (2014). Building capacity in palliative care for personal support workers in long-term care through experiential learning. International Journal of Older People Nursing, 9(2), 151-158.

8. Markle-Reid, Maureen, Orridge, Camille, Weir, Robin, Browne, Gina, Gafni, Airam, \& Lewis, Mary. (2011). Interprofessional stroke rehabilitation for stroke survivors using home care. Canadian Journal of Neurological Sciences, 38, 317-334.

9. Hall, Ruth, Khan, Ferhana, O’Callaghan, Christina, Kapral, Moira, Hodwitz, Kathryn, Kapila, Shivali Li, Shudong, Zhou, Limei, \& Bayley, Mark. (2013). Stroke evaluation report 2013: Spotlight on secondary stroke prevention and care. Toronto, ON: Institute for Clinical Evaluative Sciences. URL: http://www.ices.on.ca/ /media/Files/Atlases-Reports/2013/Stroke-evaluation-report/Full -report.ashx [January 26, 2015].

10. Lindsay, Patrice, Gubitz, Gord, Bayley, Mark, Hill, Michael, Davies-Schinkel, Corrine, \& Singh, Samantha. (2010). Canadian best practice: Recommendations for stroke care, update 2010. On behalf of the Canadian Stroke Strategy Best Practices and Standards Writing Group. Ottawa, ON: Canadian Stroke Network. URL: http://www.strokebestpractices.ca/wp-content/uploads /2011/04/2010BPR_ENG.pdf [January 26, 2015].

11. Creswell, John W. (2014). A concise introduction to mixed methods research. Thousand Oaks, CA: Sage.

12. Creswell, John W., Plano Clark, Vicki L., Gutmann, Michelle, \& Hanson, William E. (2003). Advanced mixed methods research designs. In A. Tashakkori \& C. Teddlie (Eds.), Handbook of mixed methods in social \& behavioral research (pp. 209-240). Thousand Oaks, CA: Sage.

13. Canadian Institutes of Health Research (2012). Guide to knowledge translation planning at CIHR: Integrated and end-of-grant approaches. Ottawa, ON: Canadian Institute of Health Research. URL: http://www.cihr-irsc.gc.ca/e/documents/kt_lm_ktplan-en.pdf [January 26, 2015].

14. Government of Ontario. (2015). About Ontario. URL: http://www.ontario.ca/government/about -ontario [June 12, 2015].

15. Home Care Ontario. (2015). How does the home care system work? URL: http://www.homecareontario .ca/home-care-services/about-home-care/navigating-the-system [June 12, 2015].

16. SPSS Inc. (2007). SPSS for Windows, Version 16.0. [Program]. Chicago, IL: SPSS Inc.

17. Sorrentino, Sheila A. (1996). Mosby's textbook for nursing assistants, 4th edition. St. Louis, MO: Mosby Lifeline.

18. Sorrentino, Sheila A., Remmert, Leighann, Wilk, Mary J., \& Newmaster, Rosemary. (2013). Mosby's Canadian textbook for the support worker, $3 d$ Edition. Toronto, ON: Elsevier.

19. Lofland, John, Snow, David, Anderson, Leon, \& Lofland, Lyn. (2006). Analyzing social settings: A guide to qualitative observation and analysis, 4th edition. Belmont, CA: Wadsworth Publishing.

20. Graneheim, Ulla H., \& Lundman, Berit. (2004). Qualitative content analysis in nursing research: Concepts, procedures and measures to achieve trustworthiness. Nurse Education Today, Feb 24 (2), 105-112. 
20

Framework for Integrating Unregulated Healthcare Providers into Interdisciplinary Healthcare Teams

Giosa, Holyoke, Bender, Tudge, \& Gifford
Journal of Research in Interprofessional Practice and Education

Vol. 5.2

October 2015
21. Mills, Albert J., Durepos, Gabrielle, \& Wiebe, Elden. (2010). Encyclopedia of case study research: Thematic analysis. Thousand Oaks, CA: Sage Knowledge. URL: http://studysites.uk.sagepub .com/gray3e/study/chapter23/Encyclopaedia\%20entries/Thematic_Analysis.pdf [September $11,2015]$.

22. The ADAPTE Collaboration. (2009). The ADAPTE process: Resource toolkit for guideline adaptation, Version 2.0. Perthshire, SCL: Guidelines International Network. URL: http://www.g-i-n.net /document-store/working-groups-documents/adaptation/adapte-resource-toolkit-guideline -adaptation-2-0.pdf/view? searchterm=adapte [January 26, 2015].

23. British Columbia Ministry of Health. (2007). Care Aide Competency Project: Framework of practice for community health workers and resident care attendants. URL: http://www.health.gov.bc.ca /library/publications/year/2007/CareAideCompetencyProjectFramework.pdf [January 27, 2015].

24. Clemens, Sara. (2014). Personal care best practice guidelines. Abstract submitted and presented at the OLTCA Applied Research Day, 2014. URL: https://www.eiseverywhere.com/file_uploads/0372 fdc953fa9798aed6c2e82890d56c_RD_Program2014_Feb24_Program1.pdf [January 26, 2015].

25. Estabrooks, Carole, Squires, Janet, Carleton, Heather, Cummings, Greta, \& Norton, Peter. (2014). Who is looking after mom and dad? Unregulated workers in Canadian long-term care homes. Canadian Journal on Aging, Dec 19, 1-13 (Epub ahead of print).

26. College of Physiotherapists of Ontario. (2010). Physiotherapists working with physiotherapist support personnel: Guide to the standards for professional practice. URL: http://www.collegept.org /Assets/registrants'guideenglish/standards_framework/standards_practice_guides/StandardPh ysiotherapistWorkingPhysiotherapistSupportPersonnel.pdf [January 26, 2015].

27. College of Occupational Therapists of Ontario. (2011). Standards for the supervision of support personnel. URL: http://www.coto.org/pdf/Standards_Supervision_Personnel.pdf [January 26, 2015].

28. College of Audiologists and Speech Language Pathologists of Ontario. (2007). Use of support personnel by speech language pathologists. URL: http://www.caslpo.com/sites/default/uploads/files /PS_EN_Use_of_Support_Personnel_by_SLP.pdf [January 26, 2015].

29. Lumsden, Karyn. (2013). The central west CCAC home independence program: Successfully optimizing the wellbeing of seniors in their home through inter-professional restorative care. Presentation at Health Quality Transformation Conference. Health Quality Ontario, Toronto, Ontario. URL: http://www .hqontario.ca/portals/0/Documents/home/hqt2013-session-11-en.pdf [January 26, 2015].

30. Caspar, Sienna, Cooke, Heather, O'Rourke, Norm, \& MacDonald, Stuart W.S. (2013). Influence of individual and contextual characteristics on the provision of individualized care in long-term care facilities. The Gerontologist, 53(5), 790-800. 